\title{
Prevalence of upper abdominal complaints in patients who have undergone partial gastrectomy
}

\author{
RJLF Loffeld MD PhD
}

\begin{abstract}
RJLF Loffeld. Prevalence of upper abdominal complaints in patients who have undergone partial gastrectomy. Can J Gastroenterol 2000;14(8):681-684. Little is known about the long term occurrence and prevalence of upper abdominal complaints after previous partial gastrectomy. Therefore, a retrospective, uncontrolled, cross-sectional, descriptive, clinical, endoscopic study was done. A questionnaire was mailed to patients who had undergone partial gastrectomy and been sent for upper gastrointestinal endoscopy. Eight questions were scored on a five-point Likert scale, and a symptom score was calculated. During the five-year study period, 189 patients ( 137 men, 52 women) were identified as having had a partial gastrectomy - $143(76 \%)$ received the Billroth II operation and 46 (24\%) received the Billroth I operation. The questionnaire was mailed to 124 patients, of whom 79 (64\%) responded. Eighty-eight per cent of patients had undergone surgery more than 15 years earlier. Fifty-nine patients $(75 \%)$ suffered from upper abdominal symptoms. Regurgitation of food, retrosternal heartburn and bile reflux occurred significantly more often in patients who underwent the Billroth II operation. The mean symptom score of patients who underwent Billroth I resection was significantly lower (4.5 [SD 3.6]) than that of patients who underwent Billroth II resection (7.1 [SD 4.4]) $(\mathrm{P}=0.04)$. One or more symptoms indicative of dumping were found in $70 \%$ of patients who underwent Billroth II resection and in $59 \%$ of patients who underwent Billroth I resection (not significant).

Many patients who had undergone a partial gastrectomy developed upper abdominal symptoms during long term follow-up that were not specifically linked to dumping.
\end{abstract}

Key Words: Billroth I operation; Billroth II operation; Partial gastrectomy; Upper abdominal complaints

\section{Prévalence des symptômes affectant les voies digestives hautes chez des patients qui ont subi une gastrectomie partielle}

RÉSUMÉ : On en sait peu sur l'occurrence et la prévalence à long term des symptômes affectant les voies digestives hautes après une gastrectomie partielle. C'est ce qui a poussé les auteurs à effectuer une étude clinique rétrospective, non contrôlée, transversale et descriptive à partir d'examens endoscopiques. Un questionnaire a été expédié aux patients qui avaient subi une gastrectomie partielle et chez qui on avait demandé une endoscopie des voies digestives hautes. Huit questions étaient évaluées au moyen d'une échelle de Likert en cinq points et un indice des symptômes a été calculé. Au cours de la période de cinq ans qu'a duré l'étude, 189 patients (137 hommes et 52 femmes) ayant subi une gastrectomie partielle ont été identifiés. Cent quarante-trois ( $76 \%$ ) avaient subi une opération de Billroth II et $46(24 \%)$ une opération de Billroth I. Le questionnaire a été envoyé à 124 patients dont 79 (64\%) ont répondu. Quatre-vingt-huit pour cent des patients avaient subi leur chirurgie plus de 15 ans auparavant. Cinquanteneuf patients ( 75 \%) souffraient de symptômes des voies digestives hautes : régurgitation alimentaire, sensation de brûlures rétrosternales et reflux biliaire s'observaient significativement plus souvent chez les patients qui avaient subi l'opération de Billroth II. Chez les patients qui avaient subi un résection de Billroth I, l'indice moyen des symptômes était significativement moindre $(4,5$ [É.-T. 3,6]) comparativement aux patients qui avaient subi la résection de Billroth II (7,1[É.-T. 4,4]) $(\mathrm{P}=0,04)$. On a noté un symptôme ou plus indicateur du syndrome de chasse chez 70 \% des patients qui ont subi la résection de Billroth II et chez $59 \%$ des patients qui ont subi une résection de Billroth I (non significatif).

De nombreux patients qui avaient subi une gastrectomie partielle ont développé des symptômes des voies digestives hautes durant un suivi à long terme et ces symptômes n'étaient pas spécifiquement reliés au syndrome de chasse.

Department of Internal Medicine, De Heel Zaans Medisch Centrum, Zaandam, The Netherlands

Correspondence: Dr RJLF Loffeld, Department of Internal Medicine, De Heel Zaans Medisch Centrum, PO Box 210, 1500 EE Zaandam,

The Netherlands. Telephone +31-0-75-6502779, fax+31-(0)75-6502379, e-mail R.Loffeld@chello.nl

Received for publication April 27, 2000 Accepted January 17, 2000 
$\mathrm{P}$ artial gastrectomy by the Billroth I and II operations used to be an effective therapy for ulcer disease and is still used for surgical treatment of gastric cancer. Dumping complaints, diarrhea, malabsorption and anemia are well known short term and long term side effects of the operation (1). Limited data are available on the long term outcome of partial gastrectomy with respect to the occurrence and prevalence of upper abdominal complaints (2). Therefore, a cross-sectional, descriptive, uncontrolled, clinical, endoscopic study was done to assess the prevalence of upper abdominal complaints in a population of patients who had undergone partial gastrectomy.

\section{PATIENTS AND METHODS}

In January 1998, a questionnaire was mailed to patients who were sent for upper gastrointestinal endoscopy to the endoscopy department of De Heel Zaans Medisch Centrum, The Netherlands, from 1992 to 1996, inclusive, and who had undergone a partial gastrectomy. Patients were sent because of upper abdominal complaints, dumping symptoms, anemia, gastric cancer screening or follow-up. Patients were asked whether they had experienced upper abdominal symptoms within the month before receiving the questionnaire. The questionnaire was derived from a validated questionnaire used in previous studies $(3,4)$. All patients underwent upper gastrointestinal endoscopy with Olympus EVIS 100 videoendoscopes (Olympus, Japan). The type of resection was noted, and additional endoscopic diagnoses were noted in a standardized endoscopy report. Eight questions (marked with asterisks in Table 1 ) were scored on a five-point Likert scale: $0=$ absent, $1=$ mild, $2=$ moderate, $3=$ severe and $4=$ severe and interfering with daily life. A symptom score was calculated by totalling the scores of these eight symptoms.

Hence, the minimum score was 0 (ie, no symptoms), and the maximum score was 32 (all eight symptoms severe and interfering with daily life). In addition, the mean score of each of these symptoms was determined. The minimum score was 0 (symptom absent in all patients), and the maximum score was 4 (all patients scored 4 for each symptom).

Statistical analysis was done with $\chi^{2}$ testing for contingency tables and $t$ test.

\section{RESULTS}

Over five years, 189 patients ( 137 men, 52 women) who underwent upper gastrointestinal endoscopy were identified as having undergone a partial gastrectomy - $143(76 \%)$ by the Billroth II operation and $46(24 \%)$ by the Billroth I operation. Table 2 shows the additional endoscopic diagnoses in these 189 patients. Of the 189 patients, 48 had died, and the current address of 17 was not known. Hence, the questionnaire was mailed to 124 patients, of whom 79 (64\%) responded. Additional endoscopic diagnoses in these responders were as follows: ulcer in the gastric remnant $(n=1)$, hiatal hernia $(n=3)$, reflux esophagitis $(n=2)$, gastritis $(n=3)$ and insufficient closure of the gastric cardia $(n=2)$. The time elapsed since operation is shown in Table $3 ; 70$ patients $(88 \%)$ had undergone surgery more than 15 years earlier.
TABLE 1

Presence of different upper abdominal symptoms in 17 patients with Billroth I and 42 patients with Billroth II partial gastrectomy

\begin{tabular}{|c|c|c|c|}
\hline & $\begin{array}{l}\text { Billroth I } \\
\text { n (\%) }\end{array}$ & $\begin{array}{l}\text { Billroth II } \\
\text { n (\%) }\end{array}$ & $\mathbf{P}$ \\
\hline Mean age \pm SD (years) & $64.2 \pm 7$ & $62.4 \pm 9$ & \\
\hline Age range (years) & $50-74$ & $46-81$ & \\
\hline \multicolumn{4}{|l|}{ Complaints } \\
\hline Daily & $4(23)$ & $13(31)$ & \\
\hline Weekly & $4(23)$ & $7(17)$ & \\
\hline Monthly & $7(41)$ & $16(38)$ & \\
\hline Not known & $2(13)$ & $6(14)$ & \\
\hline Epigastric pain* & $8(47)$ & $25(59)$ & \\
\hline Retrosternal pain* & $6(35)$ & $25(59)$ & \\
\hline Heartburn* & $6(35)$ & $15(36)$ & \\
\hline Retrosternal heartburn* & $6(35)$ & $28(67)$ & 0.05 \\
\hline Regurgitation* & $1(6)$ & $13(30)$ & 0.04 \\
\hline Dysphagia & $5(29)$ & $14(33)$ & \\
\hline Odynophagia & - & $1(2)$ & \\
\hline Burping & $8(47)$ & $24(57)$ & \\
\hline Fullness* & $13(76)$ & $35(83)$ & \\
\hline Pain after eating & $5(29)$ & $15(36)$ & \\
\hline Pain before eating & $1(6)$ & $5(12)$ & \\
\hline Bile taste* & $2(11)$ & $19(45)$ & 0.03 \\
\hline Halitosis & $1(6)$ & $11(26)$ & \\
\hline Meteorism & $10(59)$ & $30(71)$ & \\
\hline Nausea* & $5(29)$ & $22(52)$ & \\
\hline \multicolumn{4}{|l|}{ Appetite } \\
\hline Good & $13(76)$ & $34(81)$ & \\
\hline Bad & $4(24)$ & $8(19)$ & \\
\hline $\begin{array}{l}\text { Normal quantity of food } \\
\text { intake }\end{array}$ & $12(71)$ & $24(57)$ & \\
\hline Use of medication & $9(53)$ & $25(60)$ & \\
\hline
\end{tabular}

Only significant differences are noted. *Symptoms scored on the fivepoint Likert scale

Fifty-nine patients ( $75 \%$; 43 men, 16 women) suffered from upper abdominal symptoms, and 20 (25\%; 16 men, four women) had no symptoms; there was no significant difference in the presence or absence of complaints between men and women. Upper abdominal symptoms occurred on a daily basis in 17 patients (29\%), on a weekly basis in $11(17 \%)$ and on a monthly basis in 23 (39\%). Eight patients did not respond to the question regarding frequency of symptoms. Table 3 shows the prevalence of individual symptoms in patients who underwent the Billroth I operation and in patients who underwent the Billroth II operation. Regurgitation of food, retrosternal heartburn and reflux of bile occurred significantly more often in the patients who underwent the Billroth II operation. Mean symptom scores were significantly lower in patients who underwent Billroth I resection (4.5 [SD 3.6]) than in patients who underwent Billroth II resection (7.1 [SD 4.4])(P=0.04) (Figure 1). 
TABLE 2

The additional endoscopic diagnosis in the 189 patients with partial gastrectomy

\begin{tabular}{lc}
\hline Additional diagnosis & Number \\
\hline Reflux esophagitis & 9 \\
Ulcer in the remnant & 5 \\
Hiatal hernia & 14 \\
Gastritis & 13 \\
Stump cancer & 4 \\
Insufficient closure of the cardia & 11 \\
Hiatal hernia and esophagitis & 4 \\
\hline
\end{tabular}

TABLE 3

The time elapsed since partial gastrectomy

\begin{tabular}{lc}
\hline Time elapsed & Number of patients $(\%)$ \\
\hline$<5$ years & $1(1.2)$ \\
$5-10$ years & $6(7.6)$ \\
$11-15$ years & $2(2.4)$ \\
$16-20$ years & $3(3.6)$ \\
$21-25$ years & $11(14)$ \\
$>25$ years & $56(71.2)$ \\
\hline
\end{tabular}

Symptom scores for both groups of patients are shown in Table 4. No significant differences were noted; however, higher scores for bile reflux and retrosternal pain were seen in patients with Billroth II resection.

Dumping symptoms (vomiting, perspiring, syncope, postprandial diarrhea, palpitations and paleness) occurred in $70 \%$ of patients who underwent Billroth II resection and in $59 \%$ of patients who underwent Billroth I resection (not significant).

\section{DISCUSSION}

Partial gastrectomy has major influences on gastric physiology and function. Although it has been an effective treatment for complicated as well as uncomplicated ulcer disease, new clinical problems are seen after the operation. Apart from dumping syndrome due to the altered gastric emptying (5), reflux of bile into the gastric remnant and into the esophagus is a major cause of complaints (6). The amount of reflux from the duodenum in patients with Billroth I and II resection is significantly greater than that found in a control group of individuals with intact stomachs (7). A significant number of patients with refractory symptomatic reflux esophagitis had undergone partial gastrectomy (8). However, data on the prevalence of upper abdominal complaints are sparse. Seventy-five per cent of patients in the present study suffered from upper abdominal symptoms. At the time of endoscopy, esophagitis, obviously due to bile reflux in the esophagus, was diagnosed in $13(7 \%)$ patients, while 16 $(8.5 \%)$ others had a hiatal hernia or insufficient closure of the gastric cardia, both well known risk factors for reflux (4). One or more reflux-like symptoms were present in $58 \%$ of

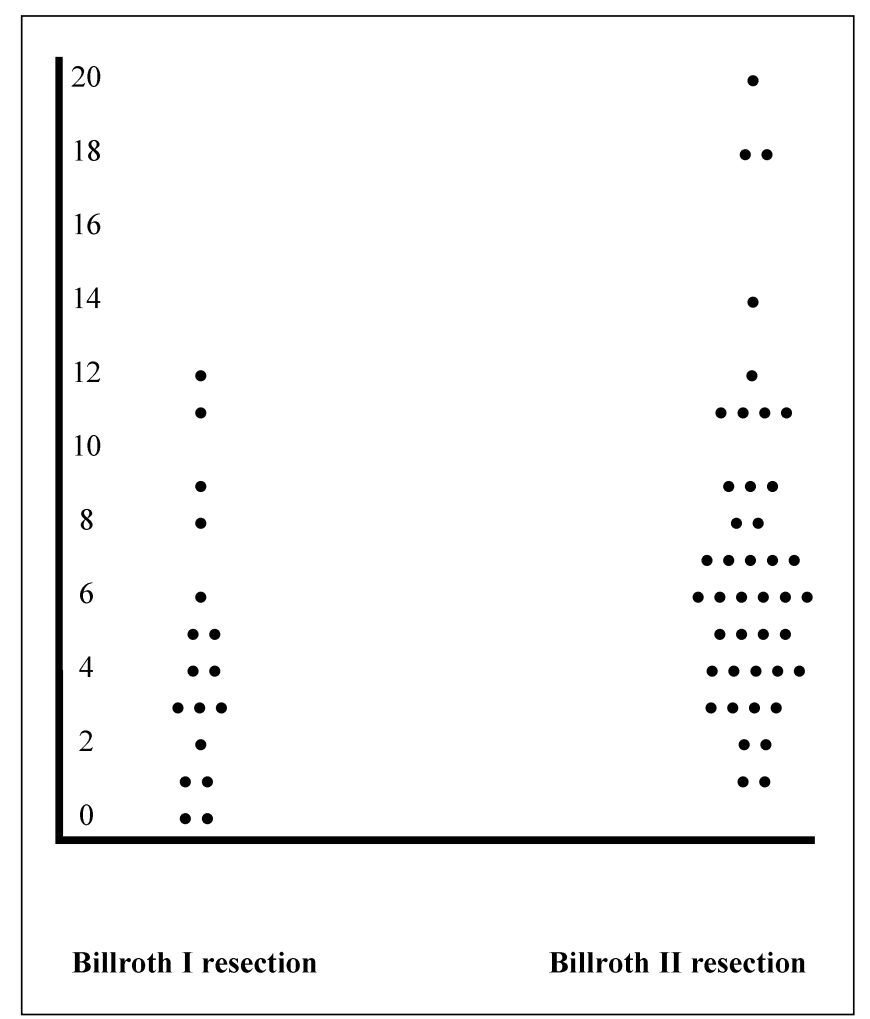

Figure 1) Scatter plot of symptom score in patients with Billroth I and II gastric resections

TABLE 4

Symptom scores (mean \pm SD) for 17 patients with Billroth I and 42 patients with Billroth II partial gastrectomy

\begin{tabular}{lccc}
\hline & $\begin{array}{c}\text { Billroth I } \\
\text { resection }\end{array}$ & $\begin{array}{c}\text { Billroth II } \\
\text { resection }\end{array}$ & P \\
\hline Epigastric pain & $0.76 \pm 0.90$ & $1.00 \pm 0.96$ & $\mathrm{~ns}$ \\
Retrosternal pain & $0.41 \pm 0.61$ & $0.90 \pm 1.09$ & 0.051 \\
Heartburn & $0.59 \pm 1.00$ & $0.59 \pm 0.88$ & $\mathrm{~ns}$ \\
Retrosternal heartburn & $0.52 \pm 0.87$ & $0.97 \pm 0.94$ & $\mathrm{~ns}$ \\
Regurgitation & $0.24 \pm 0.97$ & $0.47 \pm 0.89$ & $\mathrm{~ns}$ \\
Fullness & $1.41 \pm 0.94$ & $1.71 \pm 1.26$ & $\mathrm{~ns}$ \\
Nausea & $0.41 \pm 0.71$ & $0.83 \pm 1.01$ & $\mathrm{~ns}$ \\
Bile taste & $0.17 \pm 0.52$ & $0.62 \pm 0.88$ & 0.059 \\
\hline
\end{tabular}

Complaints were scored on the Likert scale. ns Not significant

patients. Symptom score was significantly higher, and reflux symptoms were significantly more prevalent in patients who underwent Billroth II resection than in patients who underwent Billroth I resection, obviously due to the difference in anastomosis.

A confounding factor in this retrospective study is that, because every patient was sent for endoscopy, the population was selected. Patients who never developed symptoms or who only had short lived symptoms may have been missed because they were not sent for endoscopy. On the other hand, endoscopy was performed one year or more before the 
questionnaire was sent; hence, it can be assumed that patients who had symptoms for only a short time also had the opportunity to respond. Another confounding factor is the rather few responses. Twenty-five per cent of the patients had died, mostly of old age, and the majority of nonresponders had already reached a respectable age, possibly making it difficult to fill in a questionnaire without help. Another confounding factor is that the study was not controlled. Dyspepsia is common in the general population. Use of an age- and sex-matched control group of individuals with

\section{REFERENCES}

1. Friedman LS, Peterson WL. Peptic ulcer and related disorders. In: Fauci AS, Braunwald E, Isselbacher K, et al, eds. Harrison's Principles of Internal Medicine, 14th edn. New York: McGraw-Hill, 1998.

2. Anderson ID, MacIntyre IM. Symptomatic outcome following resection of gastric cancer. Surg Oncol 1995;4:35-40.

3. Werdmuller BFM, van der Putten ABMM, Loffeld RJLF. The clinical presentation of peptic ulcer disease. Neth J Med 1997;50:115-9.

4. Werdmuller BFM, van der Putten ABMM, Loffeld RJLF. The presentation of reflux oesophagitis, hiatal hernia, Barrett's oesophagus and "reflux-like" dyspepsia: a prospective clinical and endoscopic study. Dis Esophagus 1996;9:285-9.

5. Smout AJPM, Akkermans LMA, Roelofs JMM, et al. Gastric intact stomachs would have strengthened the results of this descriptive study.

Despite that a selected, uncontrolled group of patients was studied, many patients who had undergone a partial gastrectomy, by the Billroth I or II operation, developed upper abdominal symptoms, not specifically linked to dumping, during follow-up. The incidence of upper abdominal complaints after partial gastrectomy will soon decrease given the results of modern treatment of Helicobacter pylori-associated peptic ulcer disease.

emptying and post-prandial symptoms after Billroth II resection. Surgery 1987;101:27-34.

6. Dumont A, Abramovici J, Barbier P. Quantitative analysis of diethylIDA reflux. Comparison of controls and dyspeptic, gastric ulcerated, and gastrectomized patients. Scand J Gastroenterol Suppl 1994;92:206-9.

7. Robles-Campos R, Parilla-Paricio P, Lujan Mompean JA, et al. Quantification of duodenogastric reflux in gastroduodenal peptic ulcer and in gastric operation patients using a 24-hour gastric $\mathrm{pH}$ measurement as a quantification technique. Br J Surg 1990;77:428-31.

8. Gotley DC, Ball DE, Owen RW, Williamson RCN, Cooper MJ Evaluation and surgical correction of esophagitis after partial gastrectomy. Surgery 1992;111:29-36. 


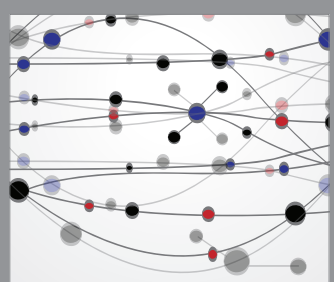

The Scientific World Journal
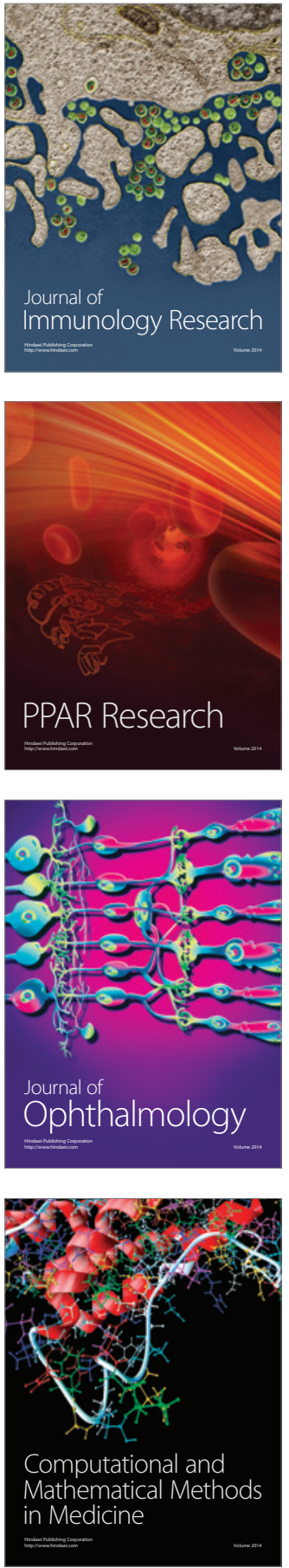

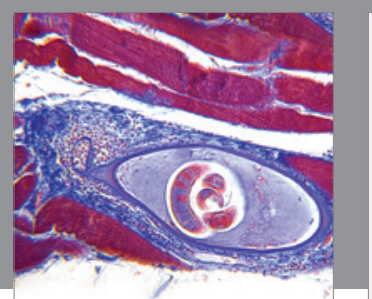

Gastroenterology Research and Practice

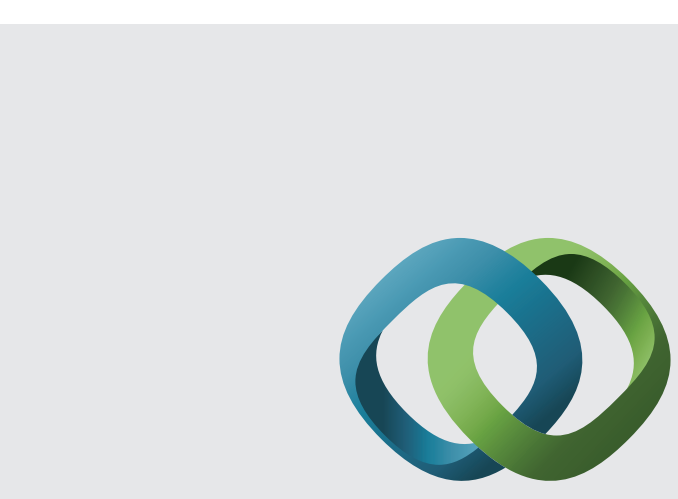

\section{Hindawi}

Submit your manuscripts at

http://www.hindawi.com
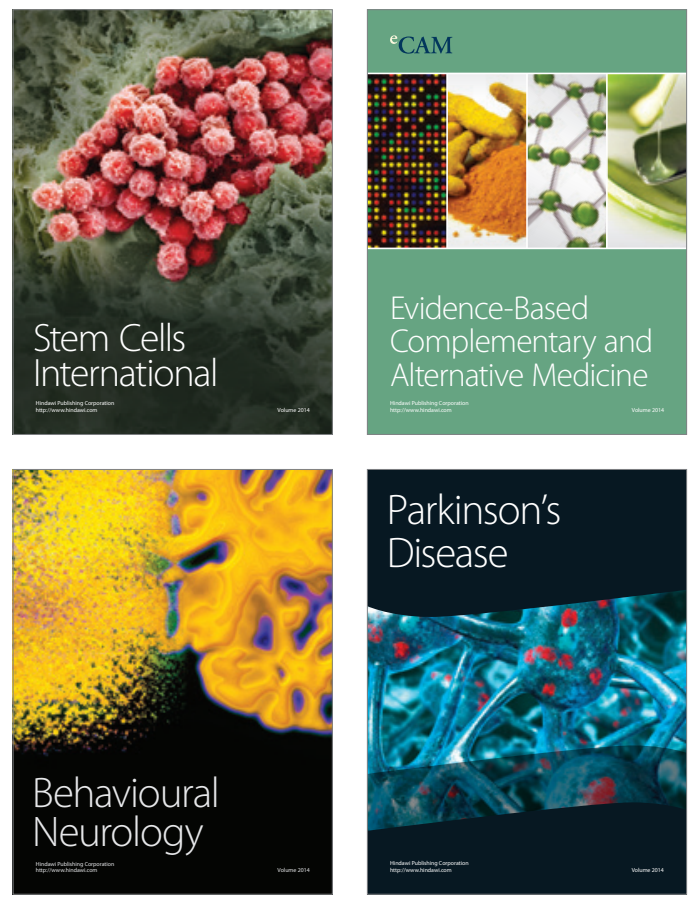
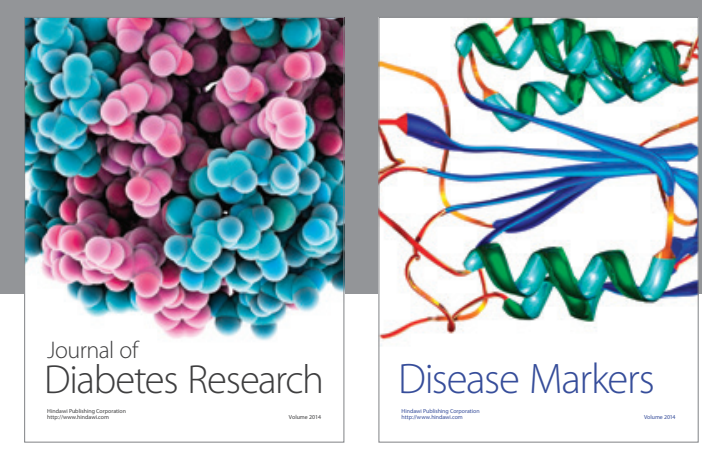

Disease Markers
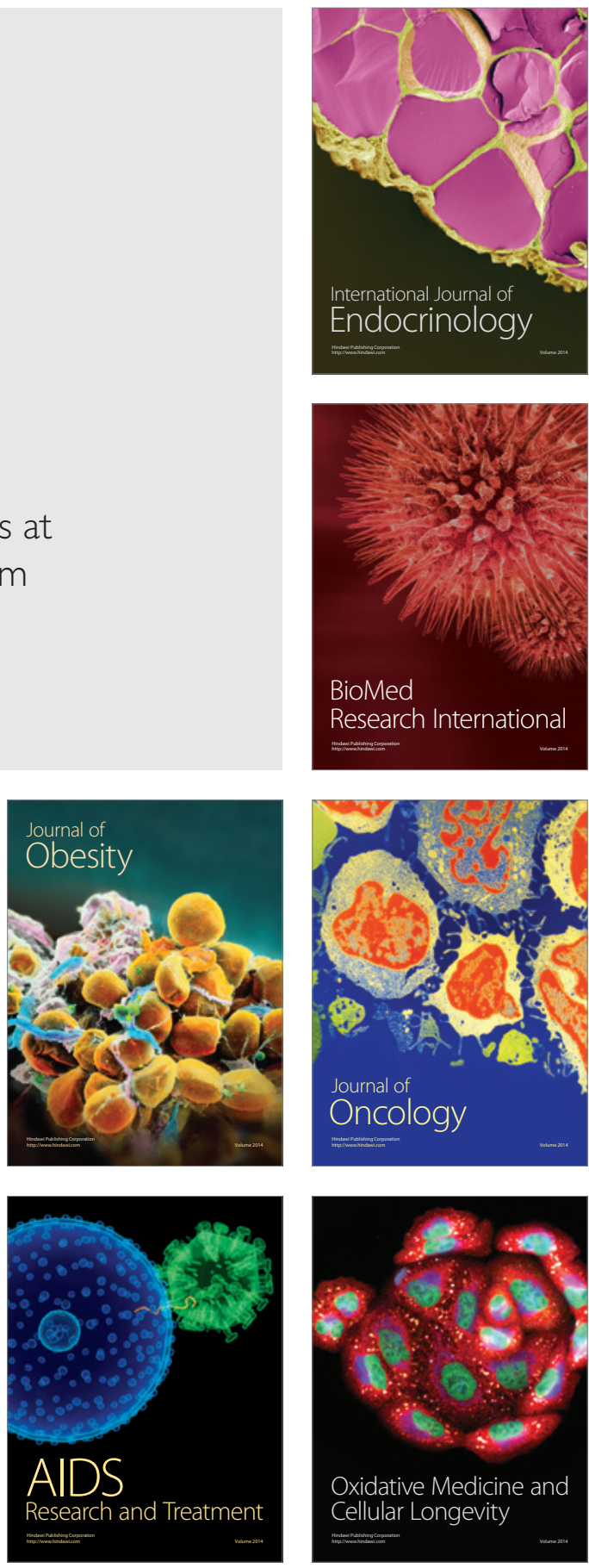